\title{
A Systematic Review and Critical Appraisal of the Quality of Studies Looking into the Economic Evaluation of Control Strategies for Soil-Transmitted Helminthiasis and Schistosomiasis
}

\author{
Fernando B. Garcia, Jr., ${ }^{1,2}$ Kate Halton-Balcon, ${ }^{2}$ Nicholas Graves, ${ }^{2}$ Lydia R. Leonardo, ${ }^{3}$ \\ Ricardo J. Soares Magalhaes, ${ }^{4}$ Archie Clements ${ }^{5}$ and Laith Yakob ${ }^{4}$ \\ ${ }^{1}$ Department of Health Policy and Administration, College of Public Health, University of the Philippines Manila \\ ${ }^{2}$ School of Public Health and Social Work, Faculty of Health, Queensland University of Technology. Brisbane, Queensland, Australia \\ ${ }^{3}$ Department of Parasitology, College of Public Health, University of the Philippines Manila \\ ${ }^{4}$ University of Queensland, Brisbane, Australia \\ ${ }^{5}$ Australian National University, Canberra, Australia
}

\begin{abstract}
Objectives. This research study aims to conduct a systematic review and critical appraisal of the quality of the existing peer-reviewed journal literature looking into the economic evaluation of control strategies used in parasitic diseases (i.e., STH and schistosomiasis).

Methods. Database searches were conducted in Embase, Science Direct, Medline, CINAHL, Econ Lit, and Academic Search Elite, by using search keywords or phrases. Using the predefined inclusion and exclusion criteria, a review of published online articles between January 1990 and December 2012 was conducted. Aside from the set of good practice guidelines in conducting economic evaluations, assessment of the quality of economic evaluations was also carried out following the Consolidated Health Economic Evaluation Reporting Standards (CHEERS) checklist.
\end{abstract}

Results. Given the inclusion and exclusion criteria set by this review, we systematically reviewed thirteen shortlisted samples of economic analysis studies. The current systematic review shows a wide variety of methodological approaches across studies, including differences in the type of economic evaluation, perspective, time horizon, approach, and adjustments for timing and certainty used.

Conclusions. In general, the economic evaluation studies that have been examined in this review have complied with the set of criteria of good practice in conducting an economic evaluation and that it can be considered helpful in making decisions and in understanding the economics of controlling these parasitic diseases.

Key Words: Economic evaluation, Soil-Transmitted Helminthiasis, Schistosomiasis, systematic review, treatment strategies

\section{INTRODUCTION}

Corresponding author: Fernando B. Garcia, Jr., PhD Department of Health Policy and Administration College of Public Health

University of the Philippines Manila

625 Pedro Gil Street, Ermita, Manila 1000, Philippines

Telephone: +6323104202

Email: fbgarcia2@up.edu.ph
Parasitic diseases, such as soil-transmitted Helminth (STH) infections, are among the most common infections worldwide causing considerable morbidity particularly in poor rural communities. High intensity and chronic infections lead to a variety of sequelae such as the negative impact on pregnancy and birth outcome, cognitive and physical development, and work capacity. Globally, there are several programs and interventions dealing with the prevention and control of parasitic diseases. Approaches to better resource allocation and planning for parasitic control must be done in a systematic way and an important tool developed is the conduct of economic evaluations that systematically assess the 
effectiveness, cost-effectiveness and impact of interventions on both patient health and the health care system. ${ }^{1}$

The recognition of the need to evaluate disease intervention strategies is evident in the growing number of economic evaluation studies being conducted and published. Evidence-based policy-making cannot solely rely on a single study thus, there is a need for policy makers and the researchers that support them to utilize all relevant studies that are already available. The huge amount of researches produced each year often yield varying findings. These between-study differences may be due to study differences, flaws or chance (sampling variation). In such situations, it is not always clear what the overall picture is, or which results are most reliable and therefore should be used as the basis for practice and policy decisions. Systematic reviews aim to address these problems by identifying, critically evaluating, and integrating the findings of all relevant, high-quality individual studies addressing one or more research questions. Although a number of economic evaluation studies on parasite control strategies have been published and made available, not all of them can be considered as valuable and useful in assisting programme managers and policy makers choose which among the competing intervention strategies has the best value for the money.

For priority setting in the field of multi-parasitic disease control strategies, there is a great demand for economic evaluation studies according to high-quality methods. Economic evaluation studies will gain value when they are of high quality and use comparable methods across the field that are in line with the methodology used for other public health issues. Therefore, it is critical to compile the existing economic evidence to reveal which methodological approaches are currently used within the field of helminthic control and prevention.

This research's objective is to conduct a systematic review of the existing peer-reviewed journal literature on the control strategies used in parasitic diseases (i.e., STH and schistosomiasis). Specifically, the aims are to:

1. examine the selected economic evaluation studies against a set of good practice guidelines in performing economic evaluations;

2. critically assess the quality of economic evaluations studies using the Consolidated Health Economic
Evaluation Reporting Standards (CHEERS) checklist; and

3. critique these selected studies in terms of their significance in decision making to equip future researchers with a deeper understanding of the economic evaluations of these parasitic disease control strategies.

\section{METHODS}

A systematic review is conducted to identify studies that evaluated health programmes and intervention on muti-parasitic diseases. The Preferred Reporting Items for Systematic Reviews and Meta-Analyses (PRISMA) guidelines were followed in this report. PRISMA is an evidence-based minimum set of items used as the basis for reporting systematic reviews and meta-analyses of researches, particularly evaluations of interventions.

\section{Search Strategy}

Online database searches were conducted in Embase, Science Direct, Medline, CINAHL with Full Text (Cumulative Index to Nursing \& Allied Health), Econ Lit, and Academic Search Elite, by using search keywords or phrases such as schistosomiasis (or Schistosoma), SoilTransmitted Helminthiasis (or helminth) cost analysis, cost-effective analysis, cost-benefit analysis, or cost-utility analysis to identify published articles that met the set predefined inclusion and exclusion criteria. Full articles were obtained and further evaluation regarding their suitability was assessed. Table 1 details the search strategy that was used for this research.

\section{Criteria used to evaluate study quality}

Using the predefined inclusion and exclusion criteria in Table 2, articles between January 1990 and December 2012 were selected. We included all published online full-text articles or manuscripts in which STH and schistosomiasis control strategies underwent full economic evaluation. Database searches were also restricted to studies written in English language that have been published between January 1990 and December 2012. We also considered both clinical trial-based evaluation and decision-analytic model in our inclusion criteria. Unlike trial-based evaluations where costs

Table 1. Details of Search Strategy

\begin{tabular}{llll} 
Search Criteria & Keywords/synonyms & Keywords/synonyms & Electronic Databases \\
& & Schistosomiasis & Schistosoma \\
Population & Soil-Transmitted Helminthiasis & Helminth & EM BASE \\
& & & Science Direct \\
& & Clinical Trial Based Evaluation & Medline \\
Intervention & Mass treatment & Decision Analytic Model & Econ Lit \\
& Targeted therapy & Cost analysis & Academic Search Elite \\
\hline Comparison & & Cost effective analysis & \\
\hline \multirow{2}{*}{ Outcomes } & DALY & Cost benefit analysis & \\
& QALY & Cost utility analysis & \\
\hline
\end{tabular}


Table 2. Inclusion and Exclusion Criteria Inclusion Criteria

- Full text of the article or manuscript is available through the identified databases;

- The study presents a full economic evaluation;

- The approach of evaluation is based on a decision-analytic model or clinical trial-based evaluations rather than case studies; and

- Written in English.

Exclusion Criteria

- Not an economic evaluation study or does not consider both the resource input (cost) and gains/outcome of the intervention;

- Dealt with case study evaluations only;

- $\quad$ Article did not include an original analysis (e.g., editorials, reviews);

- Merely confined with hypothetical data (e.g., methods articles);

- Provided partial or unclear details on methods (e.g., letters); and

- Evaluation did not involve/deal with chemotherapy as control strategy.

and effectiveness parameters are obtained from the same data collection, parameter values for modeling studies are derived from a range of sources and then combined in a decision-analytic model. Both evaluation approaches come with their own advantages and disadvantages. ${ }^{2}$ However, given the ability to include long-term costs and outcomes, side by side evaluation of all relevant competing control interventions, and it being more generalizable, modelbased evaluations are becoming more preferred approach to healthcare economic evaluations compared to trial-based evaluation. ${ }^{3}$ Nevertheless, we should take into consideration the quality, design, and unbiasedness of the models for them to be more useful in policy making. ${ }^{2}$

In performing economic evaluations, good practice guidelines have been laid down., ${ }^{4,5}$ Although there are disagreements among health economists over what constitutes good practice, broad areas of agreement are as follows: ${ }^{7}$

a. Evaluate reliability. Readers should be provided with sufficient details on how costs and effects were evaluated and measured;

b. Marginal rather than average costs should be used;

c. Options or alternatives used for comparison should be clearly stated;

d. The viewpoint or perspective of the analysis should be clearly stated;

e. Some form of discounting to either costs or effect or both; and

f. The sensitivity of the results should be explored.

This set of broad agreements of what constitutes a good practice was used to present and characterize the information that has been captured in the selected economic evaluation studies given the predefined inclusion criteria.

Aside from the guidelines mentioned above, assessing the quality of economic evaluations follow the CHEERS checklist which offers an opportunity to examine how well the published literature reported the recommended key criteria that had been identified for reporting economic analyses. This checklist is supported by the International Society for Pharmacoeconomics and Outcomes Research (ISPOR) organization and jointly endorsed by BMJ and nine other publications. ${ }^{8}$ All of the checklists have a number of key criteria in common that need to be reported in order for studies to adequately examine costs within economic analysis. The CHEERS checklist includes the following sections: (1) title and abstract [2 items]; (2) introduction [1 item)]; (3) methods [14 items]; (4) results [4 items]; (5) discussion [1 item]; and (6) other, which is related to funding and conflict of interest [2 items]. ${ }^{8}$ Not all questions can be applied to all studies as the checklist covers questions related to cost-effectiveness modeling and preference-based outcomes, which are not appropriate to all methods. However, it does specify clear criteria what the studies that purport to be economic analyses should include. Such checklists can give an indication of how well the published literature are adhering to the established guidelines and criteria for the reporting of economic analyses. A limitation to any such checklist is that it simply gives an indication of how many items have been included or excluded within an article but not the relative importance. However, it can be inferred that those articles that adhere and satisfy more criteria from the checklists are likely to be of higher quality.

\section{RESULTS}

From the initial database search, there were 139 studies that have been identified. Ninety-four studies were excluded because they were neither economic evaluation studies nor full economic evaluations. Of the remaining 45 potential economic evaluation studies, 14 were excluded because they were case studies or did not include an original analysis; 10 because they dealt with merely hypothetical data or partial/unclear details on methods; and 8 because they did not involve chemotherapy as control strategy, singly or in combination with other strategies. The shortlisted literature sample consisted of 13 economic evaluation studies that satisfied the inclusion criteria. Figure 1 shows the flow chart of the manuscript selection process.

\section{Comparison of selected components of the economic evaluation studies}

The set of broad agreements of what constitutes good practice in performing economic evaluations was used to characterize the information contained in the 13 economic evaluation studies that have been qualified given the predefined inclusion criteria. Table 3 presents the comparison 


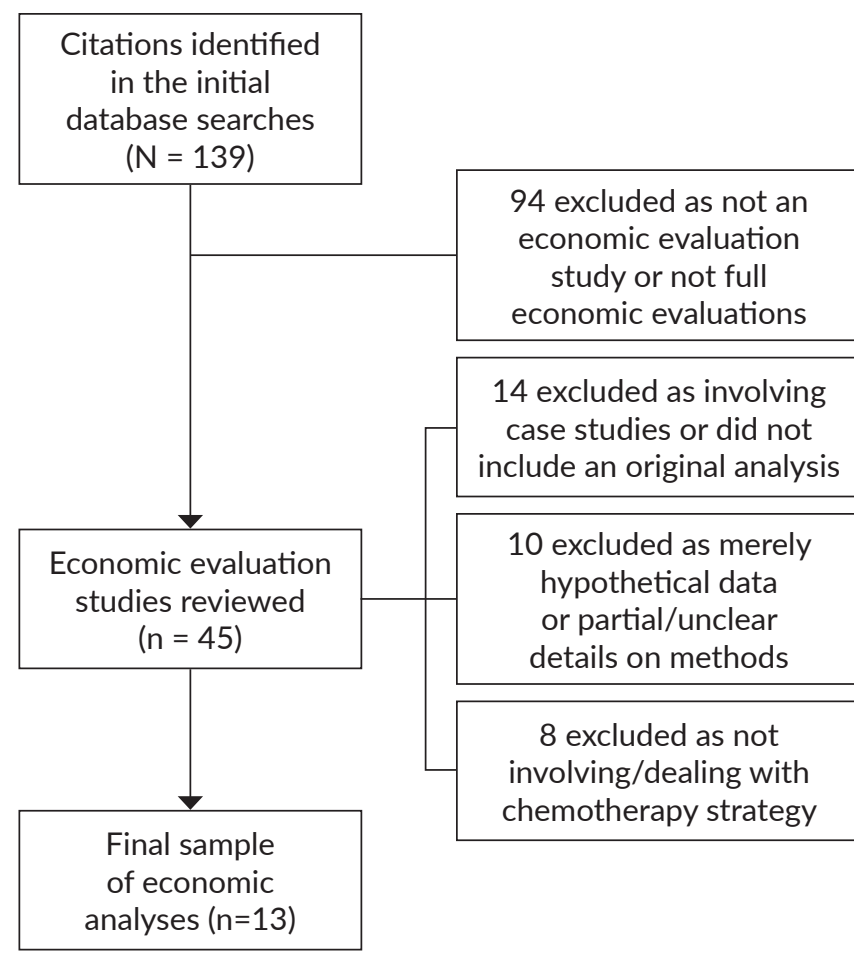

Figure 1. Prisma Flow Diagram of the Manuscript Selection Process.

of selected components or factors that have been captured in the selected economic evaluation studies. This research looked at the following components to compare what has been considered by these economic evaluation studies: a) year when the strategy intervention was implemented or carried out; b) setting of the study; c) disease or diseases looked at; d) alternatives being compared; e) evaluation approach used; f) whether marginal (or incremental) analysis was employed or not; g) to whose perspective has the study been carried out; h) type of economic evaluation analysis; i) whether discounting was employed or explicit in the study; and $\mathrm{j}$ ) presence of sensitivity analysis.

In terms of settings, $8 / 13$ (study \#1,2,4,6-10) engaged in the economic evaluation of parasitic diseases from African countries, while the rest, $5 / 13$ (study \#3,5,11-13), came from Asia. It should be noted, however, that no study from the Philippines was found. Of the thirteen studies that fitted the criteria mentioned above, seven studies $(2,3,5,8,9,12,13)$ looked at strategies for schistosomiasis and two studies $(7,11)$ for STH singly, the rest $(1,4,6,10)$ considered both diseases together. In terms of evaluation approach, 11 studies (1,3-8,10-13) applied clinical trial-based evaluation and two $(2,9)$ made use of the decision-analytic model. All of the studies (1-8,10-13) that looked at government perspective applied Cost Effectiveness Analysis (CEA) as economic evaluation ( 2 of them considered cost-benefit analysis, CBA, in conjuncture with CEA), while study (9) that considered the social perspective made use of the cost-utility analysis (CUA) to evaluate the respective strategies. Majority of the studies, 10/13 (Study \#1-3,5,6,9-13), employed marginal analysis in their evaluation while $3 / 13$ (study $\# 4,7,8)$ did not state or conduct such technique. Despite the significance of discounting costs and outcome measures as well as engaging the results to some kind of sensitivity analysis, only 6/13 $(46 \%)$ of these studies carried out such processes. Studies $(1,2,9,10,12,13)$ that carried out discounting made use of either $3 \%, 5 \%$, or $10 \%$ to costs and/or outcome measures. On the other hand, studies $(1-3,9,10,12)$ that engaged the results to some kind of sensitivity analysis made use of scenario and probabilistic sensitivity analysis. The rest of the studies did not explicitly state whether discounting or sensitivity analysis had been employed in their evaluation process.

Five studies compared alternative strategies in terms of mode of delivery (e.g., mass vs. targeted/screened) $(3,5,7,9,12)$; one study in terms of number of parasite species targetted (e.g., single- vs. multi-parasite) (6), two studies in terms of frequency (e.g., semi-annual, annual, etc.) $(8,11)$, and the remaining five studies in terms of setting (e.g., school- vs. community-based) $(1,2,4,10,13)$.

The comparison of studies in terms of mode of delivery was in a wide array: from comparing mass drug administration vs. "do nothing" ${ }^{11}$; to mass chemotherapy vs. selected strategies of the disease control methods (e.g., health education, snail control, and sanitation and water improvement) $)^{13,17}$; and to mass chemotherapy vs. targeted/ screened or selected chemotherapy. ${ }^{15,20}$ In terms of delivery, the effect of mass treatment with both albendazole and praziquantel on anemia in school-age children was evaluated. ${ }^{14}$ In terms of frequency, one study evaluated the use of oral artesunate as against the use of praziquante $1^{16}$ and the other one looked at the use of Albendazole chemotherapy on different intervals throughout the study period. ${ }^{19}$ The other five remaining studies that considered the settings in evaluating the alternatives looked at "do nothing" vs. schoolbased treatment, ${ }^{9}$ vs. combined school- and communitybased $^{12}$ vs. community chemotherapy with other control methods ${ }^{21}$; and school-based drug administration vs. schoolage targeted (at different coverage rates) ${ }^{10}$ vs. community distributed mass drug administration. ${ }^{18}$

\section{Assessment of study quality}

Figure 2 shows for each item the proportion of studies reported completely adequate, partially or not at all. The most frequent partially or not reported items were the 'measurement and valuation of preferences-based outcomes' (i.e., description of the population and methods used to elicit preferences for outcomes; item 12) and 'analytic methods' (i.e., description of all structural or other assumptions underpinning the decision-analytic model; item 17). The reporting of time horizons and choice of health outcomes could be improved (items 8 and 10). In addition, 'currency, price date and conversion' (i.e., reporting of the dates of the estimated resource quantities and unit costs and description of the methods for adjusting estimated unit costs to the year 
Table 3. Economic Evaluation Studies of STH and Schistosomiasis Control Strategies

\begin{tabular}{|c|c|c|c|c|}
\hline $\begin{array}{l}\text { Study } \\
\text { no. }\end{array}$ & $\begin{array}{l}\text { Year When } \\
\text { intervention was } \\
\text { implemented }\end{array}$ & Setting & $\begin{array}{l}\text { Disease } \\
\text { looked at }\end{array}$ & Alternatives being compared ${ }^{\mathrm{a}}$ \\
\hline 1 & 2003-2005 & Uganda & $\begin{array}{l}\text { STH and } \\
\text { Schistosomiasis }\end{array}$ & $\begin{array}{l}\text { a) "do nothing" } \\
\text { b) nationwide school-based treatment of helminth }\end{array}$ \\
\hline 2 & $\begin{array}{l}1990 \text { (published } \\
\text { empirical data } \\
\text { from studies) }\end{array}$ & Egypt & Schistosomiasis & $\begin{array}{l}\text { a) school-based ( } 85 \% \text { coverage) } \\
\text { b) school-aged targeted ( } 25 \% \text { coverage) }{ }^{*} \\
\text { c) school-aged targeted ( } 50 \% \text { coverage) }{ }^{*} \\
\text { d) school-aged targeted ( } 85 \% \text { coverage) }{ }^{*} \\
{ }^{*} \text { includes option a }\end{array}$ \\
\hline 3 & $1995-2003$ & Cambodia & Schistosomiasis & $\begin{array}{l}\text { a) "do nothing" } \\
\text { b) Schistosomiasis control program based on a Mass Drug Administration (MDA) }\end{array}$ \\
\hline 4 & $2004-2005$ & $\begin{array}{l}\text { Burkina } \\
\text { Faso }\end{array}$ & $\begin{array}{c}\text { STH and } \\
\text { Schistosomiasis }\end{array}$ & $\begin{array}{l}\text { a) "do nothing" } \\
\text { b) combined school- and community-based campaign for school-age population }\end{array}$ \\
\hline 5 & $1998-2000$ & China & Schistosomiasis & $\begin{array}{l}\text { a) traditional mass chemotherapy } \\
\text { b) 'passive chemotherapy' plus health education }\end{array}$ \\
\hline 6 & 1996-1997 & $\begin{array}{l}\text { United } \\
\text { Republic of } \\
\text { Tanzania } \\
\end{array}$ & $\begin{array}{c}\text { STH and } \\
\text { Schistosomiasis }\end{array}$ & $\begin{array}{l}\text { a) "do nothing" } \\
\text { b) school-based anthelmintic treatments (mass treatment with albendazole and } \\
\text { praziquantelon anemia in school-age children) }\end{array}$ \\
\hline 7 & $1989-1990$ & Nigeria & STH & $\begin{array}{l}\text { a) Selective chemotherapy } \\
\text { b) Targeted chemotherapy } \\
\text { c) Mass chemotherapy }\end{array}$ \\
\hline 8 & 2001-2002 & Nigeria & Schistosomiasis & $\begin{array}{l}\text { a) Chemotheraphy using praziquantel } \\
\text { b) Chemotheraphy using oral artesunate (given two doses, each of } 6 \mathrm{mg} / \mathrm{kg} \text {, } \\
\text { given } 2 \text { weeks apart) }\end{array}$ \\
\hline 9 & Not stated & Kenya & Schistosomiasis & $\begin{array}{l}\text { a) Status quo (SQS); } \\
\text { b) Household piped water supply (HPWSS); } \\
\text { c) House-to-house health education visits (HHEVS); } \\
\text { d) Household vented improved pit latrine (VIPLS); } \\
\text { e) Focal mollusciciding (FMS); } \\
\text { f) Mass population chemotherapy with praziquantel (MPCPS); } \\
\text { g) Mass population chemotherapy with oxamniquine (MPCOS); } \\
\text { h) Selective population chemotherapy with praziquantel (SPCPS); and } \\
\text { i) Selective population chemotherapy with oxamniquine (SPCOS). }\end{array}$ \\
\hline 10 & 2004 & Niger & $\begin{array}{c}\text { STH and } \\
\text { Schistosomiasis }\end{array}$ & $\begin{array}{l}\text { Mass Drug Administration (MDA) programme } \\
\text { a) School Based Mass Drug Administration } \\
\text { b) Community Distributed Mass Drug Administration }\end{array}$ \\
\hline 11 & Not stated & Bangladesh & STH & $\begin{array}{l}\text { a) Albendazole chemotherapy to all household members at the commencement } \\
\text { of the 18-mo. study period } \\
\text { b) Same as option "a" and regular education throughout the study period. } \\
\text { c) Albendazole chemotherapy to all household members at the commencement } \\
\text { of the study and subsequent chemotherapy to all children at intervals of } 6 \\
\text { months. } \\
\text { d) Same as option "c" with the addition of regular education throughout the } \\
\text { study period. }\end{array}$ \\
\hline 12 & $1998-2000$ & China & Schistosomiasis & $\begin{array}{l}\text { a) 'clue' chemotherapy (treatment to those with contact with infected water } \\
\text { and/or symptoms of infection) } \\
\text { b) 'mass' chemotherapy (treatment to all the villagers except those not able to } \\
\text { take praziquantel) } \\
\text { c) 'screen' chemotherapy (treatment prescribed to the stool egg positive cases } \\
\text { after Kato-Katz examination) }\end{array}$ \\
\hline 13 & $1992-2000$ & China & Schistosomiasis & $\begin{array}{l}\text { a) "do nothing" } \\
\text { b) Community chemotherapy plus health education and snail control by means of } \\
\text { environmental management and mollusciciding }\end{array}$ \\
\hline
\end{tabular}

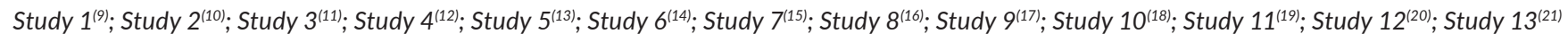

a"do nothing" refers to a situation wherein no efforts are being carried out in relation to the control of helminth infection prior to the implementation of control programme/intervention, aside from passive detection of cases in health centres and presumptive treatment. 


\begin{tabular}{|c|c|c|c|c|c|}
\hline Evaluation approach & $\begin{array}{l}\text { Marginal analysis } \\
\text { employed? }\end{array}$ & Perspective? & Analysis & $\begin{array}{l}\text { Accrued over } \\
\text { time? }\end{array}$ & Sensitivity analysis? \\
\hline clinical trial-based evaluation & Yes & Government (national provider) & CEA & $\begin{array}{c}\text { Yes, cost } \\
\text { discounted at } \\
3 \%\end{array}$ & $\begin{array}{c}\text { Scenario scenario sensitivity } \\
\text { analysis }\end{array}$ \\
\hline decision-analytic model & Yes & Government (national provider) & CEA & $\begin{array}{l}\text { Yes, a discount } \\
\text { rate of } 5 \% \text { to } \\
\text { the number of } \\
\text { cases prevented }\end{array}$ & $\begin{array}{c}\text { probabilistic sensitivity } \\
\text { analysis; one way; scenario }\end{array}$ \\
\hline clinical trial-based evaluation & Yes & $\begin{array}{l}\text { Government (national provider) } \\
\text { and the society }\end{array}$ & $\begin{array}{c}\text { EA and } \\
\text { CBA }\end{array}$ & Not stated & $\begin{array}{c}\text { probabilistic sensitivity } \\
\text { analysis; multi-way; scenario }\end{array}$ \\
\hline clinical trial-based evaluation & Not stated & Government (national provider) & CEA & Not stated & Not stated \\
\hline clinical trial-based evaluation & Yes & Government (national provider) & CEA & Not stated & Not stated \\
\hline clinical trial-based evaluation & Yes & Govern-ment (district provider) & CEA & Not stated & Not stated \\
\hline clinical trial-based evaluation & Not stated & Government (district provider) & CEA & Not stated & Not stated \\
\hline clinical trial-based evaluation & Not stated & Government (national provider) & CEA & Not stated & Not stated \\
\hline decision-analytic model & Yes & Social & CUA & $\begin{array}{c}\text { Yes, benefits } \\
\text { and costs were } \\
\text { discounted at } \\
10 \% .\end{array}$ & $\begin{array}{c}\text { probabilistic sensitivity } \\
\text { analysis }\end{array}$ \\
\hline clinical trial-based evaluation & Yes & Government (national provider) & CEA & $\begin{array}{c}\text { Yes, cost } \\
\text { discounted at } \\
3 \% \\
\end{array}$ & Scenario sensitivity analysis \\
\hline clinical trial-based evaluation & Yes & Government (district provider) & CEA & Not stated & Not stated \\
\hline clinical trial-based evaluation & Yes & Government (national provider) & CEA & $\begin{array}{c}\text { Yes, cost } \\
\text { discounted at } \\
10 \%\end{array}$ & Yes \\
\hline clinical trial-based evaluation & Yes & Government (national provider) & $\begin{array}{c}\text { CBA \& } \\
\text { CEA }\end{array}$ & $\begin{array}{l}\text { Yes, discounted } \\
\text { rate not } \\
\text { specified. }\end{array}$ & Not stated \\
\hline
\end{tabular}




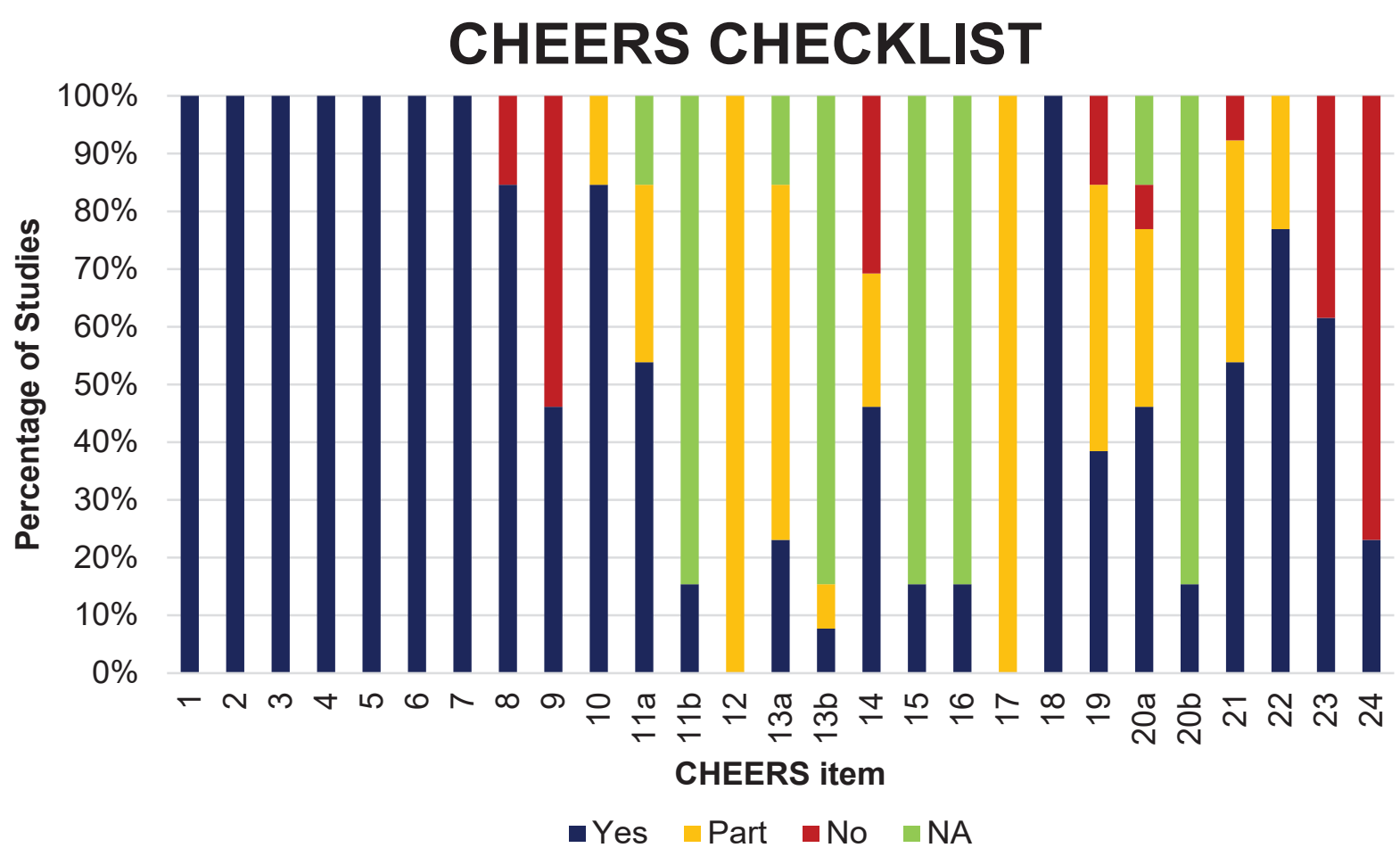

Figure 2. Quality of Reporting of CEA of Multi-Parasite Disease Control Strategies per item of the CHEERS Cheeklist.

Consolidated Health Economic Evaluation Reporting Standards (CHEERS).

NA: not applicable, No: not reported, Part: partially reported, Yes: reported

of reported costs; item 14) were not always included while comparators were sometimes considered without (proper) justification. Justification for conflicts of interest or the presence of such (item 24) is not provided in the majority of the articles. The description of approaches used to estimate resources and costs was also not complete in several articles. Also, some articles did not provide incremental costs and outcomes (item 19) and characterized uncertainty and heterogeneity (items 20 and 21). Generally, the articles discussed the key findings, limitations, generalizability, and how the findings fit with current knowledge (item 22). The source of funding and the role of the funder in the identification, design, conduct, and reporting of the analysis was only fully reported in more than half of the articles. Substantial differences in the quality of reporting were observed between articles with an average score of 18.73 out of 24 (range 13.5-21.5). Scoring is done by individually assessing the studies on whether or not they fulfill each of the CHEERS recommendations. There are studies that highly compiled the 24 recommended items whereas others have almost neglected some items.

The average scores are higher for articles published in 2008-2011 (score of 20.17) and articles published in 20002002 (score of 21). African studies reported an average score of 19.25 while studies done in Asia had an average score of 18.4. Articles with both financial and economic models have a higher reporting score (average score of 20.4) than articles that only used a financial model (average score of 18).

\section{DISCUSSIONS}

Economic evaluation of disease intervention strategies can be an effective tool for key stakeholders and policy makers in helping them decide how limited resources can be used most efficiently. A growing number of economic evaluation studies have already been published and made available looking at two of the major parasitic infections STH and schistosomiasis. Both diseases have been classified by the WHO as Neglected Tropical Diseases (NTDs) for not being prioritized in terms of treatment and research funding despite their health and economic impact, especially, in many low-income developing countries. Despite the growing number of economic evaluation studies on STH and schistosomiasis, not all of them are valuable and useful to guide various stakeholders come up with a solid decision in prudent resource allocation. Thus, it is important to examine and assess these studies into what most health economists consider as good practice in conducting economic evaluation. ${ }^{7}$

Given the inclusion and exclusion criteria set by this review, we systematically reviewed and assessed the quality of thirteen shortlisted published economic evaluation studies for the period January 1990 to December 2012 looking at STH and schistosomiasis control strategies. The current systematic review shows a wide variety of methodological approaches across studies, including differences in the type of economic evaluation, perspective, time horizon, approach, and adjustments for timing and certainty used. 
Using the guidelines of what constitutes a good practice in conducting economic evaluation, it is eminent that all of the subjected studies have complied with parameter items $a$ (sufficient details on how costs and effects were evaluated and measured), $c$ (options or alternatives used clearly stated), and $d$ (viewpoint of the analysis clearly identified). However, costs and effects under 'do nothing' baseline option for studies $1,3,4,6$, and 13 were not explicitly mentioned. It would be more valuable and useful for various stakeholders to compare the alternatives that were presented, had these values been properly identified. Furthermore, care should be properly observed in extrapolating the results of costeffectiveness studies from one setting to another primarily because Cost Effectiveness Analysis (CEA) is very context specific and is influenced by external factors such as disease prevalence; quality of service delivery; intensified case finding strategy; vector control; public health; and water, sanitation and hygiene. Validation of published resources using local data and programme costs and effects should be carried out and considered. ${ }^{2}$

It should also be noted that most of the studies have assessed intervention strategies from the government's or providers' perspective. However, a viewpoint that goes beyond that of the provider may also be needed. This is primarily because of the fact that the economic burden of STH and schistosomiasis, like any other chronic diseases, is greatest among the poorest household of the population. The importance of taking into consideration the household perspective is also supported in a case study from Bangladesh wherein the poorest households lose more time from work due to chronic diseases compared to better-off households. ${ }^{22}$ Being unproductive and unable to work when a family member becomes ill results in loss of income, sale of family's property, and/or need to borrow money to finance medication. Thus, CEA from the household perspective can be considered as crucial and as important as the other perspectives in making decisions. It can support further or alter the choice of the intervention strategy.

Majority $(10 / 13)$ of the studies employed parameter item $b$ (marginal analysis) in their evaluation process. Three studies did not employ or did not explicitly indicate in their process that such analysis had been carried out. In economic evaluation analysis, increment or decrement in programme costs and effects is more important than merely comparing their averages. Comparing programme costs and effects using absolute or averages endangers one to select an alternative strategy that is not considered as the most prudent or costeffective option when evaluated using some baseline values.

For each of parameter items $e$ (discounting) and $f$ (sensitivity analysis), less than half of the selected economic evaluation studies employ such practices. Standard practice in economic evaluations is to incorporate time preferences of current and future costs and health benefits. Discounting is the process of converting future costs to their present value, to reflect the fact that, in general, individuals and society have a positive rate of time preference for consumption now overconsumption in the future. ${ }^{23}$ Rates used from these selected studies to discount cost, effect or both varied from $3 \%(1,10)$ to $5 \%(2)$, to as high as $10 \%(9,12)$. For comparability across studies, WHO-Choosing Interventions that are Cost-Effective (WHO CHOICE) project used a discount rate of $3 \%$ for the base case. ${ }^{23}$

On the other hand, various types of sensitivity analysis (i.e., scenario, multi-way, scenario, probabilistic sensitivity analysis) have been employed not only to test how the result of the study changes if key assumptions are varied but also to explore how results behave given a hypothetical situation, the 'what if...' questions. Moreover, sensitivity analysis is used to deal with uncertainties in economic evaluations due to methodological disagreement among analysis, the study's data requirements, the need to extrapolate outcomes over time, or the desire for generalizability of the result to another setting. ${ }^{24}$

Just like any other assessment or reviews, this research has its limitations such as possible broad search strategy used for these diseases, criteria that were employed were insufficient, other parameters have been overlooked, and the fact that what has been examined are those that were only reported. Because of word limits for published studies, authors are oftentimes compelled to provide an abridged description of their study's methods. Nevertheless, assessing economic evaluation studies to some set of criteria or practices is a helpful and valuable exercise for policymakers and other stakeholders. It provides appreciation and a better understanding of the processes to be considered in order to come up with a more solid basis in choosing the intervention strategy with the best value for the money.

In addition, it is recognized that this review is coded solely by the researcher due to certain limitations. Although it was technically shown in a study ${ }^{25}$ that the use of two or more independent screeners/coders results in substantial reductions in errors in systematic review and suggests that as an 'evidence-based' practice, one should always use multiple coders unless it can provide a burden of proof that attempts were made to minimize bias and error at each step in the review process. The burden of proof is on reviewers to show that the use of a single coder does not diminish accuracy.

In a developing and low-income country like the Philippines, economic evaluations which focused on promoting equity that integrates health and social policy, underpinned by a growing understanding of the importance of social determinants of health, and integrated evaluations across systems are now developing areas of interest. However, economic evaluations in developing countries present several challenges. One potential problem is the increased interest from global funders who are concerned with assessing value for money across a range of countries is driving demand for model-based, multi-country evaluation, which may encompass dozens of countries. Moreover, novel methods are required to integrate heterogeneity in epidemiology, 
demography, unit costs, and supply and demand constraints across diverse settings in an expedient and informative way.

There is also the issue of data scarcity that is expected to remain for some time ahead. In addition, considerable investment in large-scale costing studies and further analysis of cost functions will be required to inform assessments of the costs of scaling up interventions and the generalizability of unit costs across settings. These large-scale cost surveys remain expensive; thus, further work is required to improve the efficiency and accuracy of cost-estimation methods. Further methodological development and investment are also required to support economic evaluations to inform national-level decision-making in developing countries.

The results of this study could serve as another evidence that despite available guidelines of what constitutes good practice in conducting economic evaluations, methodological issues still remain in the conduct of economic evaluation studies with regards to these diseases. It further validates serious limitations in the existing literature such as methodological quality, indefinite data, and inconsistencies of results mainly due to data sparsity, wide confidence intervals, and heterogeneity.

Future research is needed not just to examine and compare the costs and outcome measures of these economic evaluation studies, but also to look into the generation and use of evidence for economic evaluation, in particular guidance on data collection together with trials in real-world implementation. The application and further development of methods to assess the transferability of economic evaluation findings from other countries and adapt them to the local context could make a substantial contribution to increasing the use of economic evaluation results. ${ }^{26}$

\section{CONCLUSION}

After a thorough review of the articles using the CHEERS statement and the set guidelines of what constitutes good practice in conducting economic evaluations, it can be concluded that the wide array of interventions that have been considered by the selected economic evaluation studies makes it challenging to generate single conclusion across these thirteen studies. In general, however, the economic evaluation studies that have been examined in this review have complied with the set of criteria of good practice in conducting the economic evaluation. Although there were some identified concerns such as unemployment of marginal analysis, discounting, and sensitivity analysis, this should not greatly affect the concerned studies to be considered as good STH and/or schistosomiasis economic evaluation studies. Furthermore, results on the assessment of the quality of the report posted remarkable high average scores regardless of the setting and other recommended criteria for reporting economic analyses. Thus, these studies can be considered helpful in making decisions and in understanding the economics of controlling these parasitic diseases.

\section{Acknowledgments}

This research study was based on the main author's Doctoral thesis entitled, "An Economic Evaluation of MultiParasite Control Strategies in the Philippines". The research study was funded by Australia's National Health and Medical Research Council (NHMRC), as part of a larger research project grant entitled "From maps to efficient multi-parasite control in the Philippines". Views or opinions contained in this article are those of the authors and do not necessarily represent those of the Council.schools.

\section{Statement of Authorship}

All authors approved the final version submitted.

\section{Author Disclosure}

All authors declared no conflicts of interest.

\section{Funding Source}

This paper was funded by the National Health and Medical Research Council (NHMRC), Australia.

\section{REFERENCES}

1. Fox-Rushby J, Cairns J. Economic Evaluation: Open University Press, Maidenhead; 2005

2. Fryatt RJ. Review of published cost-effectiveness studies on tuberculosis treatment programmes. Int J Tuberc Lung Dis. 1997; 1(2):101-9.

3. Sculpher MJ, Claxton K, Drummond M, McCabe C. Whither trialbased economic evaluation for health care decision making? Health Econ. 2006; 15(7):677-87.

4. Drummond MF, Sculpher MJ, Torrance GW, O’Brien BJ, Stoddart GL. Methods for the Economic Evaluation of Health Care Programmes. 3rd ed: Oxford University Press; 2005.

5. Creese A, Parker D. Cost Analysis in Primary Health Care: A Training Manual for Programme Managers. Geneva, World Health Organization.1994.

6. Phillips MA, Mills A, Dye C, WHO J. Guidelines for costeffectiveness analysis of vector control: PEEM Secretariat, World Health Organization; 1993.

7. Evans DB, Hurley SF. The application of economic evaluation techniques in the health sector: the state of the art. J Int Dev. 1995; 7(3):503-24.

8. Husereau D, Drummond M, Petrou S, Carswell C, Moher D, Greenberg D, et al. Consolidated Health Economic Evaluation Reporting Standards (CHEERS) statement. BMC Med. 2013; 11:80.

9. Brooker S, Kabatereine NB, Fleming F, Devlin N. Cost and costeffectiveness of nationwide school-based helminth control in Uganda: Intra-country variation and effects of scaling-up. Health Policy Plan. 2008; 23(1):24-35.

10. Carabin H, Chan MS, Guyatt HL. A population dynamic approach to evaluating the impact of school attendance on the unit cost and effectiveness of school-based schistosomiasis chemotherapy programmes. Parasitology. 2000; 121(Pt 2):171-83.

11. Croce D, Porazzi E, Foglia E, Restelli U, Sinuon M, Socheat D, et al. Cost-effectiveness of a successful schistosomiasis control programme in Cambodia (1995-2006). Acta Trop. 2010; 113(3):279-84.

12. Gabrielli AF, Touré S, Sellin B, Sellin E, Ky C, Ouedraogo H, et al. A combined school-and community-based campaign targeting all school-age children of Burkina Faso against schistosomiasis and soil-transmitted helminthiasis: performance, financial costs and implications for sustainability. Acta Trop. 2006; 99(2-3):234-42.

13. Guo JG, Cao CL, Hu GH, Lin H, Li D, Zhu R, et al. The role of 'passive chemotherapy' plus health education for schistosomiasis 
control in China during maintenance and consolidation phase. Acta Trop. 2005; 96(2-3):177-83.

14. Guyatt HL, Brooker S, Kihamia CM, Hall A, Bundy DA. Evaluation of efficacy of school-based anthelmintic treatments against anaemia in children in the United Republic of Tanzania. Bull World Health Organ. 2001; 79(8):695-703.

15. Holland CV, O'Shea E, Asaolu SO, Turley O, Crompton DW. A costeffectiveness analysis of anthelminthic intervention for community control of soil-transmitted helminth infection: levamisole and Ascaris lumbricoides. J Parasitol. 1996; 82(4):527-30.

16. Inyang-Etoh PC, Ejezie GC, Useh MF, Inyang-Etoh EC. Efficacy of artesunate in the treatment of urinary schistosomiasis, in an endemic community in Nigeria. Ann Trop Med Parasitol. 2004; 98(5):491-9.

17. Kirigia JM. Cost-utility analysis of schistosomiasis intervention strategies in Kenya. Environ Dev Econ. 1998; 3(3):319-46.

18. Leslie J, Garba A, Oliva EB, Barkire A, Tinni AA, Djibo A, et al. Schistosomiais and soil-transmitted helminth control in Niger: cost effectiveness of school based and community distributed mass drug administration. PLoS Negl Trop Dis. 2011; 5(10):e1326.

19. Mascie-Taylor C, Alam M, Montanari RM, Karim R, Ahmed T, Karim E, et al. A study of the cost effectiveness of selective health interventions for the control of intestinal parasites in rural Bangladesh. J Parasitol. 1999; 85(1):6-11.
20. Yu D, Sarol JN Jr, Hutton G, Tan D, Tanner M. Cost-effectiveness analysis of the impacts on infection and morbidity attributable to three chemotherapy schemes against Schistosoma japonicum in hyperendemic areas of the Dongting lake region, China. Southeast Asian J Trop MedPublic Health. 2002; 33(3):441-57.

21. Zhou XN, Wang LY, Chen MG, Wang TP, Guo JG, Wu XH, et al. An economic evaluation of the national schistosomiasis control programme in China from 1992 to 2000. Acta Trop. 2005; 96(2-3):255-65.

22. Pryer J. When breadwinners fall ill: Preliminary findings from a case study in Bangladesh. IDS Bull. 2009; 20(2):49-57.

23. Tan-Torres Edejer T, Baltussen R, Adam T, Hutubessy R, Acharya A, Evans DB, et al., eds. Making choices in health: WHO guide to costeffectiveness analysis. World Health Organization. Geneva; 2003.

24. Briggs A, Sculpher M, Buxton M. Uncertainty in the economic evaluation of health care technologies: the role of sensitivity analysis. Health Econ. 1994; 3(2):95-104.

25. Buscemi N, Hartling L, Vandemeer B, Tjosvold L, Klassen, TP. Single data extraction generated more errors than double data extraction in systematic reviews. J Clin Epidemiol. 2006; 59(7):697-703.

26. Pitt C, Vassall A, Teerawattananon Y, Griffiths UK, Guinness L, Walker D, et al. Foreword: Health Economic Evaluations in Low- and Middle-income countries: Methodological issues and Challenges for Priority Setting. Health Econ. 2016; 25 Suppl 1:1-5. 